\title{
fortec's Efforts to Support Mainstream Education through Research and Technology Development
}

\author{
F.P. Seiler \\ J. Haider, P. Mayer, W.L. Zagler \\ fortec - Rehabilitation Engineering Group \\ Vienna University of Technology \\ Gusshausstr. 27/359-B, A-1040 Wien-Vienna, Austria \\ Tel.: +43/1/504 1830-21 \\ FAX: $+43 / 1 / 504$ 1830-12 \\ email: seiler@fortec.tuwien.ac.at
}

\begin{abstract}
Mainstream education of visually impaired pupils and students depends heavily on the accessibility of the same information than those available for sighted colleagues. These information are: printed text like books, lecture notes and transparents; graphics and figures are often used to illustrate or support the understanding of a verbally described procedure; and access to information available in electronic form like library catalogues, information services (e.g. gopher) and electronic texts.

fortec developed HotDot, a printing device that allows the production of Braille and/or inkprint within the same unit and on the same page. Another project is RELIEF, a new system to produce graphics and figures as hardcopy materials in tactile (three-dimensional) form. And the third project described in this paper is the conceptual design and set-up of the multifunctional VIPWorkplace for visually impaired students at the Vienna University of Technology.
\end{abstract}

\section{Introduction}

The "Working Group on Rehabilitation Engineering" (fortec) was established in 1986 at the Institute of Electronics, Vienna University of Technology, to intensify and consolidate efforts related to research and development of new technical solutions for handicapped and elderly persons.

The expertise and know-how amassed by fortec's members during the past years has made it possible to branch off in different directions. Firstly, fortec initiated numerous R\&D projects to improve the independence of disabled persons by technical solutions in the fields communication and orientation, safety aspects and daily living. Secondly, projects were started to support mainstream education on primary and university level and to develop technical-organisational concepts for special and mainstream education. Thirdly, fortec's know-how in the field of image processing and optical character recognition led to some industry related projects which deal 
with aspects of document analysis, automated document processing, scene analysis and optical process control. And finally, fortec tries to introduce rehabilitation technology in Austria and to change the society's opinion about acceptance and integration of disabled persons.

In this paper three $R \& D$ activities concerning mainstream education will be presented:

* The development of HotDot, a printing device that allows the production of Braille and/or inkprint within one single unit and on the same document. The Braille production is based on a new principle described below. Also a German language speech-output is implemented.

* The project RELIEF, a new system to produce graphics and figures as hardcopy materials in tactile (three-dimensional) form. A drawing program was developed to meet certain demands for producing tactile graphics.

* And the description of the conceptual design of the multifunctional VIPWorkplace for visually impaired students. The set-up at the Vienna University of Technology will be illustrated.

\section{HotDot - a New Technology for Braille Printers}

Usually Braille producing is based on mechanical dots which are set and unset according to the represented Braille character. These dots are embossed into sheets of paper, usually cardboard in order to have a good reading quality material. Disadvantages of common Braille printers are their weight, the produced noise and vibration/motion during embossing and the restriction to have only one output medium, namely Braille.

The need to have a multimodal output device and to produce Braille and inkprint within one device and on one and the same document which can be used by sighted as well as by blind persons initiated the project HotDot.

\subsection{Braille producing technique}

The HotDot Braille printing unit operates on a new principle, utilising heated dots which are pressed into sheets of thermoplastic material, thereby producing very little noise. The form of the Braille dots is produced by the shape of the heated dots and a mould which is positioned behind the sheet [3].

By this new Braille producing technology three goals could be achieved:

* The Braille producing device becomes very compact and lightweight so that it can be attached to an ordinary dot-matrix or ink-jet printer. Within one single unit, inkprint and Braille material can be produced, reducing cost and saving desk space.

* Due to the thermal operation the Braille producing unit works silently. Noise is caused by the motion of the sheet and, if used, by the matrix printer. If an ink-jet instead of the matrix printer is used the noise could be reduced. Additionally the printer needs little force to produce Braille, as the forming is done mainly thermal and not only mechanical. 
* The integration of the Braille producing mechanism into a state-of-the-art matrix printer offers the option to place Braille and inkprint on the same page. This technology makes it possible to have interline Braille material, where the translation into inkprint is placed beneath every line of Braille. This helps to lower the communication barrier between e.g. sighted teacher and blind student, if the teacher does not know Braille. Teacher and student can read from the same document.

\subsection{Features}

The "WineTU" translation software is directly implemented into the HotDot printer's control processor. It provides readable interline inkprint, even if the Braille text was entered in German Grade I (often used character combinations are represented by a single Braille sign) or Grade II Braille (context dependent meaning of one or two Braille characters) [6]. This occurs very often, as usually one of these forms of Braille (Grade I or II) is chosen in order to increase the text input frequency. Using Grade I Braille saves about $10 \%$, Grade II $30 \%$ in average compared to plain text entry.

In addition status information from the printer's front panel and pressing of one of the printer's function keys as well as error messages are conveyed to the user by a synthetic speech generator. This also permits the use of the HotDot printer as a speech output device instead of printing a given text. Combining tactile (Braille), audio (speech output) and inkprint, HotDot can be considered as a multimodal output device for VIPs.

\subsection{Future aspects}

A prototype model was developed. Currently we are looking for a possibility for easy and cheap production of the thermoforming elements.

Some efforts have to be done to implement the graphic mode. This would enable the printing unit to produce "primitive". tactile graphics as known from other Braille printers [5].

\section{RELIEF - CAD/CAM Production System for Tactile Graphics}

The most common way to produce tactile graphics is to build a full scale threedimensional positive model by hand and to make copies from the model (usually positive) by vacuum thermoforming. Disadvantages of this method: The manual production is very expensive as a person with experience has to build the model. Additionally this process takes a relative long time. For only one or few copies this way will not pay.

A second, very popular way is to use swell-paper, a special coated material which has the property that all black lines or areas drawn or copied onto the paper will rise when the paper is exposed to infrared heating (Minolta sells a product named SwellPaper). Disadvantages of this method: The costs per copy are linear, that means independent of the amount of produced copies. For one or few copies this is an 
advantage. Furthermore swell-paper offers only two different layers (ground and raised), so that more effects cannot be presented to the blind user. (For an overview see $[1,8]$.)

These facts lead us to find a new solution for producing more effective, easier and cheaper tactile graphics [7]. We designed RELIEF, a CAD/CAM (Computer Aided Design / Computer Aided Manufacturing) system that consists of three main components:

* a CAD-like drawing program for the design of the graphic: The needed hardcopy material is created using the specially designed and easy to use drawing program. The program has minimal hardware requirements.

* a Numeric Controlled (NC) milling machine to produce the wooden 3Dmodel: A negative three-dimensional model is shaped using the HP-GL (Hewlett Packard Graphics Language) data exchange interface. The use of negative models has been chosen because lines and Braille labelling can be accomplished much more easily and quickly with this approach. Each available NC machine with HP-GL interface can be used.

* a deep-drawing equipment for vacuum thermoforming of the foils: Using the 3D-model, as many foils as needed can be produced.

\subsection{How tactile graphics are produced using RELIEF}

The sighted teacher uses the CAD-program installed on the normally available PC at her/his school to make drawings. The data diskette is sent to the Supply Centre for Educational Material in Vienna. Here the NC machine and the deep-drawing equipment is installed. The data diskette is fed into the PC connected to the NC machine which produces a negative model of the desired drawing. In the following vacuum thermoform process, sheets of thermoplastic material are heated and deep drawn into the model.

\subsection{Features}

The heart of the entire RELIEF system is the CAD software by which sighted teachers create their drawings. As these teachers are usually inexperienced in designing tactile graphics, the $\mathrm{CAD}$ software supports them with a lot of special features to ensure acceptable results:

* Tactile graphics should not show too much detailed information. The drawing area is DIN A3 (or two times DIN A4 if desired). This is the optimal space for the perception of tactile graphics.

* The object size must have at least the size of a single Braille dot. Objects smaller than that could not be pulpated.

* It is ensured by implemented functions that two neighboured objects have sufficient distance from one another so that they can be separated by the haptic sense.

* Tactile graphics must have Braille lettering. As the teacher in most cases will not be familiar with Braille, the text can be displayed on the screen or later on 
the printout in Braille, as well as in inkprint characters which use the same space as the Braille characters.

* The CAD program offers the option of producing tactile graphics with as many as 7 distinct horizontal layers. The program, however, will make sure that the incline between elements placed in different layers will not exceed the maximum slope so that the thermoplastic material can be formed without tearing during the deepdrawing process.

* The graphic can be plot on a conventional matrix or laser printer for proofreading and for making inkprint copies for sighted pupils. Thus, it is guaranteed that the teacher, both sighted and blind pupils use identical material in the lessons.

* A standard library with often used elements and objects is available within the program. Elements can be chosen and placed on the drawing area. This library will be extended through the collected data sent to the Support Centre. Updates are distributed.

Once the teacher got used to the program, graphics can be drawn very quickly. The production of the 3D model lasts - depending on the number of objects and used layers - only about 10 minutes. The thermoforming process takes about 2 minutes per foil. The costs are very low, as standard materials (pressed wood, PVC or Polystyrol) are used. The basic equipment (PC, program, NC machine, deepdrawing equipment and first material) is available from a Viennese company. Two systems were already installed (Vienna and Berlin) and some more requests are pending.

The use of this new system by teachers is only one possibility. The easy production offers ways to more independent living for blind persons: Orientation maps of buildings or public transportation connections increase the mobility of blind travellers. Also additional tactile graphic information in user guides or manuals for technical products increase the perception of the given information.

The program won the "Deutsch-Österreichischer Hochschul-Software Preis 1993" (German-Austrian Academic University Software Award) for the best software to support education of disabled persons.

\section{VIP - Concept and Set-Up of a Hi-Tech Workplace for Visually Impaired Students}

World-wide there is a trend toward the integration of disabled students into common education. For visually impaired students the access to literature and to university infrastructure has to be provided. In many universities outside of Austria there exist support centres where students with special needs find the necessary adaptive technology and human advise [4].

Since 1991 the University of Linz (Upper Austria) offers a curriculum in computer science for blind and vision impaired students. For all other curricula, there are no special provisions to support blind and visually impaired students in Austria. Though e.g. the University of Karlsruhe (Germany) has set up a good infrastructure to support visually impaired students [2], in Austria the realisation of this concept (including psychological support) has not been possible up to now. 


\subsection{Aim of the Project}

The aim of the project VIP (which stands for 'Visually Impaired Persons') is to find a general concept for a technical support centre to allow visually impaired student to

* write texts (reports, papers, ...),

* print texts in Braille and/or ink-print,

* access information on CD-ROM or from Networks (e.g. gopher),

* browse the library catalogue,

* communicate with other students and teachers (e.g. via e-mail),

* read printed material,

* take tests and examinations,

* access available lecture notes.

After information collection about already existing support centres the first step was the selection and purchase of the necessary adaptive technology. The hardware, special developed software and organisational concept will be documented and available in order to stimulate the setting up of VIP-like workplaces at other universities within the next few years. At the Library of the University of Vienna a workplace with similar equipment was set-up in February 1994.

\subsection{Components}

VIP is a high-tech conceptual workplace for blind and visually impaired students. The VIP-workplace consists of:

* PC with CD-ROM and Magneto-Optical drive,

* Braille display,

* scanner and OCR software,

* Braille keyboard (additional to the common keyboard),

* screen review software,

* speech synthesiser,

* Braille and laser printer,

* 20 " monitor with screen enlarging software,

* software to scan documents and display magnified on the monitor,

* software for large print output on the laser printer,

* audio unit with tape deck, head phone and indexed tape recording,

* easy access to the different PC-interfaces.

Students with other or additional disabilities will profit from the adjustable desk (suited for wheelchairs) and the monitor platform, which can be moved into any desired working position. Also the use of the audio unit could be of profit for hard of hearing students e.g. to listen once again to recorded lectures.

In order to have maximum flexibility in providing different levels of authorised access and to interact with peripheral units (printers, data communication lines, etc.) from one or, if necessary, from more user PCs, a client/server architecture has been chosen. 


\subsection{Conclusion}

To increase the mobility of visually impaired students we suggest to install VIP-like workplaces at other universities. Being familiar with one of the VIP-Workplaces should enable the visually impaired student to immediately use any other VIPWorkplace without additional training.

The technical support centre should allow to be run on a self-service basis as far as possible. In addition to the technical equipment it is necessary to have human advise. In the last year in Austria counsellors were installed at some universities. This trend should be completed in order to have personal support at Austrian universities for students with special needs.

\section{Acknowledgements}

The projects mentioned in this paper have been supported by the Austrian National Bank (Oesterreichische Nationalbank) and by the Austrian Federal Ministry of Education and the Arts (Bundesministerium für Unterricht und Kunst).

\section{References}

1. Emiliani, P.L.: Production of Hardcopy Materials for the Blind. In: Proceedings of the European Workshop; Florence; (1989).

2. Klaus, J.: Integrating Blind and Visually Handicapped Students into University Learning and Living: A Pilot Project at the University of Karlsnuhe. In: Proceedings of the 6th Annual Conference "Technology and Persons with Disabilities", Los Angeles; 525-535; (1991).

3. Mayer, P., Busboom, M., Ehrenfels, G., Zagler, W.L.: HotDot - A Combined Braille- and Inkprint Printing Device. In: Proceedings of the Third International Conference on Computers for Handicapped Persons, Oldenbourg, Vienna; 338-343; (1992).

4. Murphy, H.: The Use of Computers by University Students with Disabilities. In: Computers for Handicapped Persons; Oldenbourg, Vienna; pp. 61-68; (1989).

5. Nater, P.: DOTGRAPH - a Drawing Program for a Conventional Braille Printer. In: Proceedings of the Third International Conference on Computers for Handicapped Persons, Oldenbourg, Vienna; 373-381; (1992).

6. Seiler, F.P., Oberleitner, W.: WineTU, German Language Grade 2 to ASCII Braille Translator. In: Journal of Microcomputer Applications, Academic Press, Vol. 13; 185-191; (1990).

7. Seiler, F.P., Grünfelder, R., Deisenhammer, H.: Producing Hardcopy Graphics for Blind or Visually Impaired Persons Using a Special Drawing Program Called RELIEF. In: Journal of Microcomputer Applications, Academic Press; Vol. 16; 301-306; (1993). 
8. Witte, R.F.V.: Production of Hardcopy Materials for the Blind; Proceedings of the European Workshop; Toulouse; (1989). 